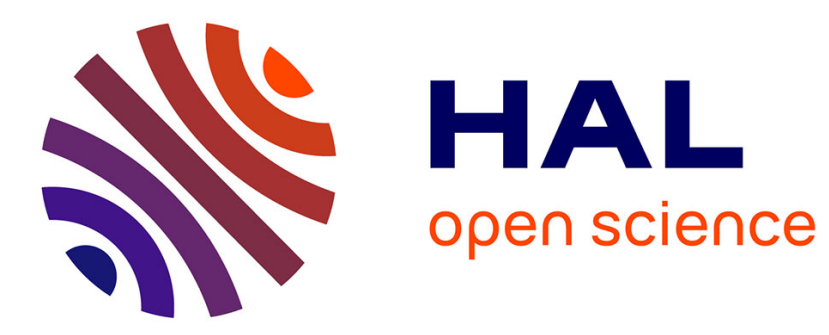

\title{
Parental investment in the Columbian ground squirrel: empirical tests of sex allocation models
}

\author{
Thibaut Barra, Vincent Viblanc, Claire Saraux, Jan Murie, F. Stephen
}

Dobson

\section{- To cite this version:}

Thibaut Barra, Vincent Viblanc, Claire Saraux, Jan Murie, F. Stephen Dobson. Parental investment in the Columbian ground squirrel: empirical tests of sex allocation models. Ecology, 2021, 10.1002/ecy.3479 . hal-03299142

\section{HAL Id: hal-03299142 \\ https://hal.science/hal-03299142}

Submitted on 26 Jul 2021

HAL is a multi-disciplinary open access archive for the deposit and dissemination of scientific research documents, whether they are published or not. The documents may come from teaching and research institutions in France or abroad, or from public or private research centers.
L'archive ouverte pluridisciplinaire HAL, est destinée au dépôt et à la diffusion de documents scientifiques de niveau recherche, publiés ou non, émanant des établissements d'enseignement et de recherche français ou étrangers, des laboratoires publics ou privés. 


\section{Parental investment in the Columbian ground squirrel: empirical}

\section{tests of sex allocation models}

3

4 Thibaut Barra $^{1 *}$, Vincent A. Viblanc ${ }^{*}$, Claire Saraux ${ }^{1}$, Jan O. Murie ${ }^{2}$ \& F. Stephen Dobson ${ }^{1,3 \phi}$ 5

$6 *$ Equal contribution

7

${ }^{1}$ University of Strasbourg, CNRS, Institut Pluridisciplinaire Hubert Curien, UMR 7178, 67000

9 Strasbourg, France

$10 \quad{ }^{2}$ Department of Biological Sciences, University of Alberta, Edmonton, AB T6G 2E9

$11{ }^{3}$ Department of Biological Sciences, Auburn University, 311 Funchess Hall, Auburn, AL 36849

12

13

14

15

16

17

18

19

20

$21{ }^{\phi}$ Corresponding author: F Stephen Dobson, Department of Biological Sciences, University of

Alberta, Edmonton, AB T6G 2E9; fsdobson@msn.com

23

24 Running head: Sex allocation models in a wild mammal 


\section{ABSTRACT}

Parental allocation of resources into male or female offspring and differences in the balance of offspring sexes in natural populations are central research topics in evolutionary ecology. Fisher (1930) identified frequency-dependent selection as the mechanism responsible for an equal investment in the sexes of offspring at the end of parental care. Three main theories are proposed for explaining departures from Fisherian sex ratios in light of variation in environmental (social) and individual (maternal condition) characteristics. The Trivers-Willard (1973) model of male-biased sex allocation by mothers in the best body condition is based on the competitive ability of male offspring for future access to mates and thus superior reproduction. The local resource competition model is based on competitive interactions in matrilines, as occur in many mammal species, where producing sons reduces future intrasexual competition with daughters. A final model invokes advantages of maintaining matrilines for philopatric females, despite any increased competition among females. We used 29 years of pedigree and demographic data to evaluate these hypotheses in the Colombian ground squirrel (Urocitellus columbianus), a semi-social species characterized by strong female philopatry. Overall, male offspring were heavier than female offspring at birth and at weaning, suggesting a higher production cost. With more local kin present, mothers in the best condition biased their offspring sex ratio in favor of males, and mothers in poor condition biased offspring sex ratio in favor of females. Without co-breeding close kin, the pattern was reversed, with mothers in the best condition producing more daughters, and mothers in poor condition producing more sons. Our results do not provide strong support for any of the single-factor models of allocation to the sexes of offspring, but rather suggest combined influences of relative maternal condition and matriline dominance on offspring sex ratio.

Keywords: Kin selection, local resource competition, matrilines, sex ratio allocation, Trivers-Willard hypothesis 
51 Life-histories are a central focus of both ecology and evolution (Stearns 1992; Roff 2001). The success of different life history strategies can be assessed through individual variations in fitness (characteristics of reproduction and survival), and the expression of traits contributing to higher reproductive and survival rates (e.g., Endler 1986; Kruuk and Hill 2008). The fitness differences of individuals that carry different trait forms, in turn, depend on the interactions of those traits with the ecological and social environments (e.g., Lande and Arnold 1983). Thus, our understanding of evolution rests on a foundation of ecological interactions that produce fitness differences (Hutchinson 1965). An aspect of reproduction that might result in fitness differences among individuals is the differential allocations of resources that parents make to male and female offspring. Such allocation differences might lead to variations in offspring sex ratio, if the fitness returns of producing males or females differ, depending on the environment.

In many animal species, offspring sex ratios are close to even, a generality that Darwin (1871) puzzled over. Fisher (1930) pointed out that it is not the numbers of male and female offspring that should be roughly equal in a population, but the amount of parental allocation of resources. Fitness returns of allocating resources to a male or female offspring should be equal in bisexual species, since every individual has a mother and father and in turn will potentially become a mother or father. In other words, the fitness returns of male and female offspring are equal. When the ratio of male to female offspring allocation varies from even, frequencydependent selection should bring it back into balance. If both sexes are equally costly to produce, then an even sex ratio of offspring should occur (Fisher 1930, Charnov 1979). Nonetheless, extremely biased offspring sex ratios have been found in nature (e.g., Hamilton 1967) and hypotheses for explaining adaptive deviations from so-called "Fisherian sex ratios" have been subsumed into a theory of how resources are allocated between the sexes 
of offspring (Charnov 1982, Frank 1990, West 2009). In an early attempt at predicting biases from even sex allocations, Trivers and Willard (1973) suggested that mothers should vary in their body condition and ability to invest in offspring. If the future reproductive success of one sex is more variable than that of the other and can be influenced by augmented early investment, then mothers in better body condition should invest more in that sex. For instance, suppose that male future reproductive success is more variable than female future reproductive success, and is augmented by enhanced development early in life as in most polygynous and polygynandrous mammal species (Dobson 1982, Dobson et al. 2010). Then, mothers in relatively good body condition should produce more males, and mothers in relatively poor condition should produce more females. This hypothesis assumes that the relative cost of producing male and female offspring differs, that there is a positive association of maternal body condition and the production of males, that early investment in males should persist into adulthood, and that such males should have greater fitness as adults. Despite considerable empirical and theoretical study of offspring sex ratio in mammals (Clutton-Brock and Iason 1986; Festa-Bianchet 1996; Kojola 1998; Hewison and Gaillard 1999, Brown 2001; Cameron 2004; Cameron et al. 2008; Schindler et al. 2015; Toni et al. 2021), support for the prediction of a positive association of maternal condition and offspring sex ratio remains equivocal.

Clark (1978) developed the idea of local competition among relatives as an influence on offspring sex ratios that deviate from 50:50 to explain offspring sex ratios that typically vary between $60-75 \%$ male in species such as galagos (Galago sp.) and African wild dogs (Lycaon pictus). She noted that females are often limited in reproduction by competition over local resources, such as food, refuges from predation, or territories (reviewed by Emlen and Oring 1977). This competition should favor production of the dispersing sex. In polygynous and polygynandrous mammals, females are often highly philopatric and matrilineal, and the dispersing sex among juvenile and subadults is usually males (Greenwood 1980, Dobson 
1982). When population density is already high, females should thus produce more males to

101 prevent future local competition for resources. Several studies have provided empirical support

102 for the local resource competition model, including primates (Clark 1978), marsupials

103 (Cockburn et al. 1985; Schwanz and Robert 2014), and rodents (Wells and Van Vuren 2017).

104 Silk (1983) expanded on this model by suggesting different maternal allocations to male

105 and female offspring according to maternal dominance status. Dominant, high-condition,

106 mothers able to tolerate increased local resource competition may benefit from producing

107 female offspring in greater proportion to ensure matriline dominance, especially in species

108 where females exhibit cooperative breeding. In contrast, subordinate adult females should

109 produce more dispersing sons to lower the costs of local competition. Support for this

110 hypothesis has been found in social rodents (Armitage 1987a) and primates (Silk 1983;

111 Simpson \& Simpson 1982; Johnson 1988) (reviewed by Cockburn et al. 1985).

112 Biases in offspring sex ratios under the above hypotheses are expected to primarily

113 result from differences in the fitness payoffs of producing or allocating resources to male or

114 female offspring. The allocation of resources by parents might be best measured at the

115 termination of parental care (Fisher 1930; Trivers and Willard 1973). However, in matrilineal

116 species like social mammals, maternal investment can be extended throughout the lifespan,

117 making estimation of maternal allocation of resources difficult. In addition, differential

118 survival of offspring during the period of parental investment may cause a skew in allocation

119 to the sexes (Austad 2015). Finally, the ecological and social influences on both allocation of

120 resources to offspring and on offspring sex ratios are not mutually exclusive, so that more than

121 one hypothesis might be supported in any particular species (e.g., Kruuk et al. 1999; Cockburn et al. 2002; Delean et al. 2009; Yeo \& Hare 2021).

124 of offspring energy allocation and sex ratio. They are semi-social, hibernating sciurid rodents 
125 that inhabit subalpine meadows in the Rocky Mountains of southwestern Canada (Boag and

126 Murie 1981; Dobson et al. 1992). Within colonies, philopatric females overlap temporally and

127 spatially with close kin, creating local matrilines (King and Murie 1985; King 1989a, 1989b).

128 Females with higher numbers of kin acquire direct and indirect fitness benefits from philopatry

129 (Viblanc et al. 2010; Arnaud et al. 2012; Dobson et al. 2012). Males, on the other hand, 130 contribute little or nothing to the production of offspring beyond sperm, during a short mating season (Manno and Dobson 2008; Raveh et al. 2010, 2011), and exhibit high variance in reproductive success (Raveh et al. 2010). Mothers are variable in size and body condition (Dobson 1992; Dobson et al. 1999; Rubach et al. 2016), and thus provide suitable variables for testing hypotheses about allocation of resources to offspring and variation in offspring sex ratios. The amount and quality of food resources are a major influence on allocations to offspring by mothers (Dobson and Kjelgaard 1985; Dobson and Muri 1987; Dobson 1988). Finally, year-to-year environmental variations are extreme (Lane et al. 2012, Dobson et al. 2016), thus providing ample variation in annual availability of resources. The purpose of our study was five-fold. First, we tested the repeatability of offspring 140 sex ratio over the lifetimes of adult females, to examine trait flexibility. Second, we evaluated the costs to mothers of producing male and female offspring. We examined the estimated costs of sons and daughters in terms of their mass at weaning, a value that should reflect the energetic costs of producing offspring. We also examined the fitness costs of producing sons and

144 daughters for mothers, by testing for differences in maternal reproduction, survival and mass gain during the active season. Third, we tested the Trivers and Willard (1973) prediction that mothers in good condition should produce costlier sons. For this, we focused on female mass

147 at the start of the breeding season, known to strongly influence subsequent reproductive success

148 (Dobson et al. 1999; Broussard et al. 2005; Rubach et al. 2016). We tested if females in good 149 condition biased maternal investment towards males. Fourth, we tested Clark's predictions 
150 from the local resource competition hypothesis of male-biased offspring production when local 151 density and competition for resources are high within matrilines (Clark 1978). Fifth, we 152 examined Silk's (1983) prediction that females in the best body condition and in large 153 matrilines should produce sex ratios biased towards daughters, since they can best bear costs

154 associated with local resource competition and reap the benefits of augmented matrilines 155 (Armitage 1987a,b).

We used a 29-year long-term data set of known female reproductive allocations including litter size and offspring mass at birth and weaning, maternal mass at the start of the reproductive season, and matriline genealogies that reveal close kin relationships between

159 Columbian ground squirrels, to empirically test models of allocation of resources to the sexes 160 of offspring. The data set on offspring sex ratio from parturition to offspring weaning, uniquely allowed distinguishing between offspring sex ratio at birth and at about the time that the major period of maternal care ended, and differential maternal allocation to (and survival of) the sexes over the period of parental care.

\section{MATERIALS AND METHODS}

\section{STUDY SITE AND LONG-TERM MONITORING}

167 Data were collected from 1992 to 2020 at a 2.6 ha subalpine meadow in the Sheep River 168 Wildlife Provincial Park, Alberta, Canada (50³8’10’N, 114³9’56’W, 1550m asl).

169 Columbian ground squirrels were monitored yearly throughout the breeding season from 170 emergence from hibernation ( mid-April) to weaning of the offspring ( early July). In each 171 year of the study, all animals were trapped when first emerging from hibernation, using live traps (Tomahawk Live Trap Co., Hazelhurst, WI; $13 \times 13 \times 40 \mathrm{~cm}$ ) baited with a small amount of peanut butter. Ground squirrels were weighed to the nearest $5 \mathrm{~g}$ using a Pesola ${ }^{\circledR}$ spring-slide scale, given a unique ear tag number (\#1-Monel metal; National Band and Tag Company, 
175 Newport, KY), and painted with a unique dorsal mark on the pelage for visual identification at a distance, using black human hair dye (Clairol, Stanford, CT).

Females typically estrous cycle within 3-5 days after emergence from hibernation, and are sexually receptive for a few hours on a single day (Murie and Harris 1982, Murie 1995, Raveh et al. 2010). We determined mating date for each female from behavioral observations, inspection of their genitalia, and the presence of copulatory plug material in or around the vulva (Murie and Harris 1982). Mated females were caught 22 days after mating, 2-3 days before expected parturition, and transported to a $1.5 \mathrm{~km}$-distant field laboratory where they gave birth. Females were housed in polycarbonate microvent cages $(47$ x 27 x $20 \mathrm{~cm}$; Allentown Caging Equipment Company, Allentown, NJ), and provided wood chip bedding and shredded newspaper for nesting material. Food, including grains (a molasses-enriched horse feed), fresh apples, fresh lettuce and water were provided ad libitum twice a day. At birth, mothers (nearest $5 \mathrm{~g}$ ) and pups (nearest $0.01 \mathrm{~g}$ ) were weighed. Pups were sexed and marked with a small tissue biopsy used for establishing paternities (Hare and Murie 1992). The biopsy created a partial claw loss on a rear foot, and thus pups could be identified at birth and later at weaning. Newborns and their mothers were released approximately one day after birth into their nest burrow, known from behavioral observations of females stocking them with dry grass prior to capture and marked with colored flags.

Entire litters and mothers were caught 27-28 days after birth, when young first emerged from nest burrows near the time of weaning. Young were then ear tagged for permanent identification and weighed to the nearest $1 \mathrm{~g}$. Mothers were weighed again to the nearest $5 \mathrm{~g}$. Since 1992, several generations of matrilineal genealogies are known from mother-offspring associations. Complete life histories (including age and pedigree relationships) are known for the vast majority of animals that lived on the study site. For each year of the study, we used the long-term data to determine: (1) offspring sex ratio and individual mass at birth and at weaning, 
and sex ratio variation among adult females, (2) female condition and energy allocation to offspring in grams of body mass, and (3) the density of closely related kin.

\section{OFFSPRING SEX RATIO}

204 We calculated offspring sex ratio at birth and at weaning as the proportion of males produced

205 in a litter: $S R=\frac{\text { males }}{(\text { males }+ \text { females })}$. Because some females did not give birth in the lab (especially 206 in earlier years of the study, and after 2017), sample sizes differ between sex ratio at birth and 207 at weaning. To characterize partial litter loss over the course of lactation, we further calculated 208 the difference between sex ratio at weaning and sex ratio at birth for females having lost at 209 least one offspring between birth and weaning: $\Delta S R=S R_{\text {wean }}-S R_{\text {birth }} . \Delta S R$ varied 210 between -0.67 and 0.75 (mean \pm s.d. $=0.00 \pm 0.26, \mathrm{n}=102$ litters).

\section{DATA ANALYSES}

213 All analyses were conducted in the R statistical computing environment v. 4.0.2 (R Core Team

214 2020). Results are presented as means \pm 1 S.E., unless otherwise noted. Independent variables 215 were standardized prior to analyses, so that coefficients were directly comparable as effect 216 sizes. Where appropriate, we examined model residuals for normality by visual inspection of 217 density distributions, Q-Q plots, cumulative distribution functions and P-P plots using the 218 “fitdistrplus" package in R (Delignette-Muller \& Dutang 2015). We also insured that no 219 substantial collinearity occurred between independent variables (all variance inflation factors $220<3$; suggested cut-off, see Zuur, Ieno \& Elphick 2010). The goodness-of-fit of each model was 221 evaluated by comparing the deviance of the model to the deviance of the null model (with the 222 intercept only) and expressed as explained deviance $E D=\frac{\text { deviance }_{\text {null }}-\text { deviance }_{\text {model }}}{\text { deviance }_{\text {null }}}$, characterizing the percent-deviance explained by the model. 


\section{Repeatability of offspring sex ratio}

226 For females that bred in multiple years, we estimated offspring sex ratio repeatability using the

227 "rptR" package in R (Stoffel et al. 2017). Repeatability was calculated as $R=\frac{V_{G}}{V_{P}}=\frac{V_{G}}{V_{G}+V_{R}}$,

228 where $V_{G}$ is the among-group variance, $V_{R}$ is the residual variance, and $V_{P}=V_{G}+V_{R}$ is the total phenotypic variance in offspring sex ratio. $V_{G}$ was either the among-individual variance or the among-year variance, depending on whether repeatability within females or within years was considered. Variance in offspring sex ratio was decomposed using separate generalized linear mixed-effects models (GLMM, 'lme4' package in R; Bates et al. 2015), with offspring sex ratio specified as a proportion of successes and failures for each mother as the dependent variable (count data; matrix of "success" and "failures" with male = "success", female =

"failure"), and mother identity or year as a random factor. Confidence intervals around repeatability estimates were calculated by parametric bootstrapping $(\mathrm{N}=1000$ random data sets were generated from the distribution defined by the estimated parameters). As the amount of variance in offspring sex ratio explained by mother ID or year was virtually zero, we disregarded these factors as random variables in subsequent models on sex ratio.

\section{Cost differences in male and female offspring}

Differences in the energy invested in the production of male and female offspring

243 First, we tested for differential energy costs in the production of male/female offspring production by comparing male and female mass at birth and at weaning. Offspring mass at birth and at weaning were specified as dependent variables in separate linear mixed models (LMMs), and offspring sex was included as an independent factor. We controlled for litter size at birth (mean \pm s.d. $=3.22 \pm 0.87, \min =1, \max =7)$ as a covariate in all models because of the known trade-off between number and mass of offspring in our species (e.g., Dobson et al. 1999; Skibiel et al. 2009). Mother ID and litter ID were included as random variables in the 
models to account for repeated measures over the years, and the non-independence of offspring born from the same mother and raised within the same litter. We also tested if female and male offspring differed in their survival from birth to weaning using a binomial GLMM. Offspring survival was included as the dependent variable (binary; survived $=1$, died $=0$ ) and offspring sex as the independent variable of interest. We further accounted for litter size and offspring mass at birth in the model as known influences on survival. As above, mother ID and litter ID were originally included as random variables in the models to account for repeated measures over the years, and the non-independence of offspring born from the same mother and raised within the same litter. However, mother ID explained virtually no variance in pup survival, and was removed from the final model.

Fitness costs to mothers

Second, we tested if maternal fitness costs could be detected for mothers that invested more into male or female-biased litters. We considered the effects of litter sex ratio at birth, or at weaning, on 3 proxies of maternal fitness: (1) reproductive output over the season (litter size at weaning; count data, mean \pm s.d. $=2.54 \pm 1.28$ offspring, $\min =0, \max =7$; Poisson GLMM), (2) maternal mass gain (or loss) over the breeding season (continuous data, mean \pm s.d. $=108.7$

$267 \pm 46.8 \mathrm{~g}, \min =-50 \mathrm{~g}, \max =280 \mathrm{~g} ; \mathrm{LMM}$ ), and (3) mother survival (binary, 0/1; binomial 268 GLMM) to the next year. We initially included mother ID, age and year as random factors in the models to account for variance in fitness parameters, but removed these when the variance explained was virtually null.

\section{Testing Trivers and Willard's model of sex allocation}

273 Maternal condition effects on litter sex ratio

274 We used a 3-step analysis to test for maternal condition effects on sex ratio. 
First, to test whether mothers that raised a litter, on average, biased the offspring sex

towards males in particularly favorable years, we calculated the average mass of breeding

277 females at emergence from hibernation (mean \pm s.d. $=419.72 \mathrm{~g} \pm 20.70 \mathrm{~g}$, $\min =376.6 \mathrm{~g}$, $\max$

$278=460.55 \mathrm{~g}$ ), and the average sex ratio (see Fig 1) at weaning for the population, for 28 years of the 29 year-study (no data on maternal mass in 2020 due to COVID-19). We then regressed mean offspring sex ratio at weaning on mean maternal mass at emergence (LM; $\mathrm{N}=28)$. at emergence of hibernation on offspring sex ratio at weaning. For this, we used a generalized linear model (GLM) specifying offspring sex ratio as a proportion of successes and failures for each mother and as the dependent variable, and maternal mass at the start of the season as the independent variable. Further, considering only females having lost at least one offspring during lactation, we tested the effects of maternal body mass at emergence from hibernation on the change in offspring sex ratio from birth to weaning ( $\Delta \mathrm{SR})$ by regressing $\Delta \mathrm{SR}$ on maternal mass at emergence. We also tested if the proportion of offspring (dependent variable, binomial proportion GLM) lost during lactation for individual mothers, controlling for litter size at birth, depended on maternal body mass at emergence. where they were in particularly good condition compared to their lifetime average, we calculated relative maternal mass at emergence within a year, i.e. female mass compared to her mean mass over the years she weaned a litter. This annual relative condition index (mean \pm s.d. $=0.00 \mathrm{~g} \pm 30.60, \min =-133.00 \mathrm{~g}, \max =106.43 \mathrm{~g})$ was calculated as:

$$
\text { annual relative } \text { condition }_{i, y}=\text { mass }_{i, y}-\mu_{i} \text {, }
$$


specifying offspring sex ratio as a proportion of males and females for each mother and as the dependent variable, and annual relative condition as the independent variable.

\section{Maternal condition effects on male and female offspring mass gain}

We tested whether the gain in offspring mass over the course of lactation for males

$($ mean \pm s.d. $=97.34 \mathrm{~g} \pm 22.14, \min =45.04 \mathrm{~g}, \max =198.06 \mathrm{~g})$ and females $(92.12 \mathrm{~g} \pm 19.57$

$\min =35.82 \mathrm{~g}, \max =169.61 \mathrm{~g})$ was differently affected by maternal condition at the start of the breeding season. We used a linear model (LM) with offspring mass gain specified as the dependent variable, and maternal mass at emergence from hibernation, offspring sex and the interaction between offspring sex and maternal mass at emergence specified as independent variables. In addition, we controlled for litter size at birth, offspring mass at birth, and lactation duration (mean \pm s.d. $=26.27$ days $\pm 1.12, \min =23$ days, $\max =31$ days $)$ as covariates in the model, because they were possible influences on offspring mass gain.

\section{Testing local resource competition models of sex allocation}

\section{Clark's model of local resource competition}

315 To test Clark's (1978) prediction that mothers should bias offspring sex ratio towards the

316 dispersing (male) sex when local kin competition for resources is high, we performed a two-

317 step analysis. First, we tested if offspring sex ratio was biased towards males (the dispersing sex) in years of high population density. For this, we calculated the average sex ratio (see Fig 1) at weaning for the population, and regressed it on overall population density (mean \pm s.d. $=$ 62.69 individuals $\pm 22.87, \min =32$ days, $\max =120$ days; $N=29$ years). Second, we used the long-term matrilineal genealogies to determine the total number of kin females (mothers, daughters, and littermate sisters) in each year of the study (mean \pm s.d. $=0.89 \pm 0.72, \min =0$, $\max =4)$. We restricted our analyses to reproductive females only, defined as females that 
mated and were potentially able to hold a territory at some point during the breeding season

325 (Festa-Bianchet and Boag 1982, Murie and Harris 1988). We subsequently examined litter sex ratio at weaning and changes in offspring sex ratio from birth to weaning (LM; $\Delta \mathrm{SR})$ in relation to the numbers of kin present in the population (independent variables). We also tested if the proportion of offspring (dependent variable, binomial proportion GLM) lost during lactation by individual mothers, controlling for litter size at birth in the model, depended on the numbers of kin present in the population.

\section{Silk's model of matriline dominance}

333 To test Silk's (1983) prediction that dominant females in relatively good body condition (i.e.,

334 who can best incur the costs of local resource competition with kin) should produce sex ratios biased towards daughters, we further examined the interaction between maternal condition relative to other females and kin numbers. Here, we calculated relative condition as the differential between the mass of a mother and the mean mass of all females in the population at the start of the breeding season in a given year. Lactating females are socially dominant over other ground squirrels (Murie and Harris 1988), females in better body condition produce larger and heavier litters (Dobson et al. 1999), and mothers with the greatest reproductive investments are socially dominant (Viblanc et al. 2016). Condition relative to other females (mean \pm s.d. $=$ $0.00 \mathrm{~g} \pm 49.51$, range $=-191.25 \mathrm{~g}$ to $174.23 \mathrm{~g})$ was calculated as:

$$
\text { relative } \text { condition }_{i, y}=\text { mass }_{i, y}-\mu_{y} \text {, }
$$

344 where $i$ is mother ID and y is year. A relative condition $>0($ or $<0)$ would indicate that a female 345 was in relatively better (or worse) condition than other females of the population in a given 346 year. Relative condition increased in a quadratic fashion with age, so that, on average, it was $<$

3470 for females until 4 years, increased up until 6-7 years old, before decreasing afterwards (see 348 Appendix S1), consistent with previous quadratic relations found for dominance-related 
aggression and age in this species (Viblanc et al. 2016). We subsequently examined litter sex ratio at weaning (GLM, binomial) and changes in offspring sex ratio from birth to weaning $(\mathrm{LM} ; \Delta \mathrm{SR})$ in relation to a female's relative condition, the number of kin present in the population, and the interaction between both variables (independent variables).

\section{RESULTS}

\section{REPEATABILITY OF OFFSPRING SEX RATIO}

At termination of parental care (weaning), offspring sex ratio in our population was on average

$51.3 \%$ male ( $\mathrm{n}=1581$ offspring, $\mathrm{N}=195$ mothers), ranging from $36.2 \%$ in 2020 to $74.2 \%$ in

2009 (Fig. 1). The estimated repeatability of offspring sex ratio was virtually nil both when considering inter-individual variation (binomial GLMM; $R=0.000 \pm 0.006, \mathrm{CI}_{95}=[0.000-$ 0.022], $n=622$ litters, $N=203$ mothers $)$, and when considering inter-annual variation $(R=$ $0.007 \pm 0.006, \mathrm{CI}_{95}=[0.000-0.021], n=622$ litters, $N=29$ years $)$.

\section{COST DIFFERENCES BETWEEN MALE AND FEMALE OFFSPRING}

\section{Differences in the energy invested in the production of male and female offspring}

At birth, controlling for litter size, male offspring were $4.15 \%$ heavier than female offspring

(Fig 2A; Appendix S2: Table S1A). Similarly, at weaning and when controlling for litter size, male offspring were $3.61 \%$ heavier than female offspring (Fig 2B; Appendix S2: Table S2B).

368 Controlling for litter size and offspring mass at birth, male and female offspring did not differ significantly in their survival rates $(75 \%$ for males, $76.8 \%$ for females; Appendix S2: Table S2) from birth to weaning. Offspring survival was positively associated with offspring mass at birth $(z$-mass odds ratio $=+1.86 \pm 0.16$, Appendix S2: Table S2), but not significantly with

372 litter size at birth ( $z$-litter size odds ratio $=+1.20 \pm 0.25$, Appendix S2: Table S2). 
375 When testing for costs to mothers, maternal reproduction (litter size weaned) was not significantly related to litter sex ratio at birth (GLMM, with Poisson error term; odds ratio = $\left.0.87 \pm 0.09, \mathrm{CI}_{95}=[0.71,1.07], z=-1.34, P=0.18, \mathrm{n}=415\right)$ or at weaning $\left(0.94 \pm 0.07, \mathrm{CI}_{95}\right.$

$378=[0.81-1.10], \mathrm{t}=-0.76, \mathrm{P}=0.45, \mathrm{n}=559)$. Maternal survival to the next year was neither significantly influenced by litter sex ratio at birth (GLMM, with binomial error term; odds ratio $\left.=0.98 \pm 0.39, \mathrm{CI}_{95}=[0.45-2.13], \mathrm{z}=-0.05, \mathrm{P}=0.96, \mathrm{n}=415\right)$ or at weaning (odds ratio $=$ $\left.1.08 \pm 0.35, \mathrm{CI}_{95}=[0.57-2.05], \mathrm{z}=0.24, \mathrm{P}=0.81, \mathrm{n}=536\right)$. Maternal mass gain over the season was positively, but not significantly, related to litter sex ratio at birth (LMM; $8.44 \pm$ 7.83, $\left.\mathrm{CI}_{95}=[-6.90-23.78], \mathrm{t}=1.08, \mathrm{P}=0.28, \mathrm{n}=350\right)$, and tended to be positively associated with litter sex ratio at weaning $\left(9.81 \pm 5.39, \mathrm{CI}_{95}=[-0.75-20.37], \mathrm{t}=1.82, \mathrm{P}=0.07, \mathrm{n}=508\right)$. Thus, for a 1\%-point increase in litter sex ratio at weaning (e.g. from 50 to $51 \%$ male), maternal mass gain over the course of reproduction increased by 0.098 grams, on average.

\section{TESTING TRIVERS AND WILLARD’S MODEL OF SEX ALLOCATION}

\section{Maternal condition effects on sex ratio}

Over 28 years, the mean sex ratio at weaning of offspring in the population (Fig 1) was not significantly associated with mean maternal mass at the start of the breeding season (LM; $z$ mean female mass $=-0.01 \pm 0.02, t=-0.41, \mathrm{CI}_{95}=[-0.04,0.03], P=0.69, \mathrm{~N}=28$ years $)$. offspring sex ratio at weaning (GLM; binomial; $z$-mass odds ratio $=0.88 \pm 0.09, \mathrm{CI}_{95}=[0.74$, 1.04], $z=-1.46 ; P=0.15, n=1499, E D=0.29 \%)$. Similarly, for females that lost at least one offspring over lactation, maternal body mass did not significantly affect changes in offspring sex ratio from birth to weaning $\left(\mathrm{LM}\right.$; z-mass $=+0.03 \pm 0.03, \mathrm{CI}_{95}=[-0.02,0.08], t=1.11, P=$ 
proportion of offspring lost during lactation was not significantly related to maternal mass at emergence (GLM binomial; odds ratio: $\mathrm{z}$-emergence mass $=0.96 \pm 0.07, \mathrm{CI}_{95}=[0.84-1.10]$, $P=0.57, n=1336, E D=0.03 \%)$.

When considering maternal yearly condition index (maternal yearly mass relative to her lifetime average), mothers did not seem to bias litter sex ratio differently in years when they were in relatively better or worse condition compared to their lifetime average (GLM; $z$ yearly condition odds ratio $=0.96 \pm 0.05, \mathrm{CI}_{95}=[0.86,1.06], z=-0.84, P=0.40, n=1499, E D$ $=0.1 \%$ ). Maternal yearly condition also did not seem to significantly affect changes in

407 offspring sex ratio from birth to weaning, for those mothers that lost young during lactation 408 $\left(\mathrm{LM} ; z\right.$-yearly condition $=0.01 \pm 0.03, \mathrm{CI}_{95}=[-0.04,0.07], t=0.54, P=0.590, n=102, E D$ $409=0.29 \%$.

\section{Maternal condition effects on mass gain of male and female offspring}

412 Regardless of sex (non-significant interaction, Appendix S2: Table S3A), offspring mass gain over lactation was positively related to maternal mass at the start of the breeding season $(z$ maternal mass $=+3.42 \pm 1.28)$, to offspring mass at birth (z-offspring mass birth $=+4.40 \pm$ $0.44)$, to lactation duration ( $z$-lactation duration $=+4.48 \pm 0.66)$, and negatively related to litter size at birth ( $z$-litter size birth $=-7.58 \pm 1.08)$ (Fig 3; Appendix S2: Table S3B). Controlling for these effects in the model (Appendix S2: Table S3B) male offspring gained $1.68 \%$ more mass than females over lactation (Fig. 3A). The absence of an interaction between maternal body mass and offspring sex suggests no differential allocation to males and females according to maternal condition. Taken together, the results do not provide strong support for Trivers and Willard's model of sex allocation in Columbian ground squirrels. 
425 Offspring sex ratio at weaning was not significantly associated with population size over the course of our study $\left(\mathrm{LM} ; z\right.$-population density $=-0.02 \pm 0.02, t=-1.16, \mathrm{CI}_{95}=[-0.05,0.02], P$

$427=0.25, \mathrm{~N}=29$ years) (Appendix S2: Figure S1). Offspring sex ratio at weaning was positively 428 and significantly, though weakly, associated with a female's kin numbers in a given year $429\left(\mathrm{GLM} ; z\right.$-kin odds ratio $=+1.10 \pm 0.05, \mathrm{CI}_{95}=[1.00,1.21], z=2.05, P=0.040, n=1371, E D$ $430=0.6 \%$ ). This effect appeared to be mediated through differential mortality of male and female 431 offspring during lactation, since offspring sex ratio at birth was not significantly related to a 432 female's kin numbers in a given year (GLM; $z$-kin odds ratio $=+1.02 \pm 0.05, \mathrm{CI}_{95}=[0.92$, 1.11], $z=0.30, P=0.764, n=1243, E D=0.02 \%$ ). Indeed, for females that lost at least one offspring over lactation, kin numbers were positively, though weakly, associated with changes in offspring sex ratio from birth to weaning $\left(\mathrm{LM} ; z\right.$-kin $=+0.05 \pm 0.03, \mathrm{CI}_{95}=[-0.00,0.10], t$ $=1.87, P=0.065, n=97, E D=3.5 \%$ ). Controlling for litter size at birth (all VIFs $<1.01)$, the overall proportion of offspring lost during lactation was not significantly related to kin numbers (GLM binomial; odds ratio: $z$-kin $=1.08 \pm 0.07, \mathrm{CI}_{95}=[0.95-1.23], P=0.22, n=1246, E D$ $=0.18 \%$ ). Taken together, these results appear to provide some support for local resource competition as an influence on sex ratio in Columbian ground squirrels.

\section{Silk's model of matriline dominance}

Adding maternal body mass relative to female conspecifics in a given year and its interaction with kin numbers to the above models revealed a significant interaction between maternal relative condition and kin numbers affecting sex ratio at weaning (Fig 4; $z$-maternal relative condition $\mathrm{x} z$-kin odds ratio $=+1.18 \pm 0.06, \mathrm{CI}_{95}=[1.06,1.33], t=2.88, P=0.004, n=466$; see Appendix S2: Table S4A; ED = 2.1\%). The proportion of males in weaned litters increased with maternal condition relative to other females within a year, but only when kin numbers 
were high (with 2 or more co-breeding female kin). It was only when kin were absent that mothers in relatively good condition produced more daughters (Fig 4). Changes in offspring sex ratio from birth to weaning, in contrast, did not seem to be significantly affected by the interaction between maternal relative condition and kin (Appendix S2: Table S4B). Removing the interaction did not reveal any effect of maternal relative condition (z-maternal relative condition $\left.=+0.00 \pm 0.00, \mathrm{CI}_{95}=[-0.00,0.00], t=1.26, P=0.21, n=97\right)$, but indicated a subtle effect of kin numbers $\left(z\right.$-kin $=+0.04 \pm 0.02, \mathrm{CI}_{95}=[-0.00,0.08], t=1.93, P=0.056, n=97$, $E D=5.1 \%)$ on changes in sex ratio from birth to weaning $(\Delta \mathrm{SR})$. These results do not seem to support Silk's model of matriline dominance in Columbian ground squirrels.

\section{DISCUSSION}

As predicted by Fisher (1930), and over 29 years of study, offspring sex ratio at the end of parental care in Columbian ground squirrels was roughly even at $51.3 \%$ male. However, sex ratio varied markedly, from $36.2 \%$ to $74.2 \%$ male (repeatability was virtually null) among years, suggesting scope for trait responses to variations in maternal, social, and ecological conditions. We tested three hypotheses proposed to explain deviations from Fisherian sex ratios in the animal realm from an adaptive perspective: the Trivers and Willard (1973), Clark (1978), and Silk (1983) models of maternal allocation to male and female offspring. These hypotheses are not mutually exclusive, but make different predictions about parental allocations to male and female offspring that can influence offspring sex ratio. Trivers and Willard (1973) focused on female energy allocation. For Columbian ground squirrels, where increased maternal condition is related to increased reproductive output (Dobson and Kjelgaard 1985; Dobson and Murie 1987; Dobson 1988; Risch et al. 1995; Dobson et al. 1999; Skibiel et al. 2009), they

472 predict a positive association between maternal body condition and male offspring production.

473 In contrast, Clark (1978) focused on local resource competition, predicting an increased 
474 production of the dispersing sex (males) when local competition is high. Finally, Silk (1983)

475 made the opposite prediction of Trivers and Willard (1973), in that behaviorally dominant

476 females in good condition (in our case, indexed by higher body mass relative to other females)

477 should produce females to enhance the benefits of matrilines.

478 The Trivers and Willard (1973) hypothesis was not well supported by our results for

479 Columbian ground squirrels (but see Schindler et al. 2015), although the conditions for this

480 hypothesis were generally met. Offspring sex ratio was close to Fisher's (1930) even

481 expectation at about 51\%. Males seemed slightly more energetically expensive to produce,

482 because they were about $4 \%$ heavier than females. However, they incurred no detectable fitness

483 costs to mothers. Part of this mass difference was accounted for by differential growth during

484 lactation, when young are under ground and solely dependent on the mother for sustenance.

485 This condition likely persists into adulthood, since males are both larger and heavier than

486 females at every age (Dobson 1992). Heavier males obtain advantageous matings and produce

487 more offspring (Raveh et al. 2010; Balmer et al. 2019). Thus, we could examine the prediction

488 that more should be invested in males by mothers with the greatest breeding resources. Female

489 ground squirrels breed primarily from daily resource consumption, but their resources at the

490 start of the spring breeding season have a significant influence on reproduction (Dobson et al.

491 1999; Broussard et al. 2005; Rubach et al. 2016).

492 Adult female condition at near the time of conception is most likely to influence

493 offspring sex ratio (Cameron et al. 1999; Cameron 2004; Sheldon and West 2004; Cameron

494 and Linklater 2007). However, we found no significant pattern for male-biased litters in years

495 where the mean condition of females in the population was higher at the beginning of the spring

496 breeding season. Also, there was no significant association between individual maternal body

497 mass at the beginning of the spring breeding season and either sex ratio of young at weaning,

498 or change in sex ratio of young between birth and weaning for mothers that lost young during 
499 lactation. Finally, individual mothers did not produce male-biased litters in years when they

500 were in better condition compared to their lifetime average, as the Trivers-Willard (1973)

501 hypothesis would predict. The Trivers-Willard hypothesis appears well supported in some taxa

502 and weakly or not supported in others (Cameron 2004; Robert and Schwanz 2011; Schindler

503 et al. 2015; Douhard et al. 2016; Hamel et al. 2016; Douhard 2017). Identification of the

504 underlying reasons for such variation (e.g., phylogeny, social structure, food availability,

505 environmental constraints) might be evident in a meta-analysis of published results on sex ratio

506 and the Trivers-Willard hypothesis.

507 We found a weak, but significant, association between kin numbers and sex-ratio at

508 weaning. The proportion of males in a litter increased by a factor 1.15 (unstandardized odds

509 ratio) for a 1 unit increase in kin numbers in the population. In other words, for one extra

510 breeding kin in the population, sex ratio would increase by $15 \%$, for instance from $50 \%$ male

511 to $57.5 \%$ male. This observation is consistent with Clark's (1978) model of local kin

512 competition. Clark's hypothesis was devised to explain a strong overall male bias in the

513 offspring sex ratios of species such as galagos and African wild dogs. To avoid competition

514 with close relatives, Clark (1978) suggested that breeding females in such systems might

515 produce more sons, if males were the predominant dispersing sex. For species without a strong

516 overall sex bias in numbers of offspring, however, the hypothesis still makes predictions about

517 the preferential production of the sex of offspring by mothers with respect to kinship, when

518 resources are in short supply. In Columbian ground squirrels, females with co-breeding close

519 relatives, like mothers, daughters, and sisters, live in close proximity in matrilines (Arnaud et

520 al. 2012; Dobson et al. 2012), whereas subadult males are predominant dispersers (Wiggett and

521 Boag 1992; Neuhaus 2006). Closely related adult females have the potential for competition

522 with respect to using environmental resources, but the presence of close co-breeding female

523 kin clearly benefits reproduction and fitness (Viblanc et al. 2010; Dobson et al. 2012). 

neighbors on offspring sex ratio, but argued that mothers in good condition should produce more daughters to maintain and promote advantages associated with the matriline of closely related kin, while mothers in poor condition should produce more males to avoid additional competition. Silk's (1983) hypothesis was that dominance matters in primate species, such that dominant females produced more daughters and subordinate females produced more sons that dispersed from their natal groups. In Columbian ground squirrels, adult females are individually territorial, but show both material and fitness benefits to living close to cobreeding relatives, despite the possibility of reproductive competition. Material benefits include lowered aggression, and closer proximity of more easily-defendable territories (Harris and Murie 1984; King and Murie 1985; King 1989a, 1989b; Arnaud et al. 2012). Fitness benefits of proximity to close relatives include improved individual reproductive success (Viblanc et al. 2010) and augmented inclusive fitness via a substantial indirect fitness component (about 40\%; Dobson et al. 2012). Thus, it is reasonable to predict that adult females in the best condition and social circumstances (viz., surrounded by close kin) should produce 539 daughters. When considering maternal body mass relative to other females in a given year, we

541 found that the presence of female kin was associated with offspring sex ratio bias. Mothers in 542 better body condition produced slightly more sons, but only when more co-breeding close kin 543 were present. The opposite pattern occurred for mothers that started the season in relatively 544 poor condition. This would seem to contradict Silk's (1983) ideas about promotion of the matriline through the birth of daughters to adult females in good condition, but support Clark's

546 (1978) idea that mothers in matrilines that suffer from resource competition should produce 547 more of the dispersing sex among their offspring. Further support for Clark's (1978) hypothesis 548 of the influence of local resource competition was somewhat present in adult females that 
549 suffered a partial litter loss. These females tended to produce more males as the number of co550 breeding female close kin increased (with an associated trend towards greater juvenile male 551 survival from birth to weaning), as might be expected if they invested more in males to avoid 552 future resource competition. Silk (1983) suggested that competitive mothers reduce daughter 553 production of subordinate females via harassment. In Columbian ground squirrels, lactating mothers in better body condition produce larger and heavier litters (Dobson et al. 1999), and are known to be socially dominant (Murie and Harris 1988; Viblanc et al. 2016). On the other hand, harassment as a result of aggression and infanticide is biased towards non-kin in this species (King 1989a, Stevens 1998, Viblanc et al. 2016), and whether the selective mortality of daughters we observed with increasing kin numbers during lactation resulted from increased female harassment towards subordinate kin remains unclear. golden mantled ground squirrels (Callospermophilus lateralis) had increasing male-bias at weaning with increased numbers of nearby close kin, though older females surrounded by many kin had offspring sex-ratios biased towards females. Armitage (1987a), working with

564 yellow-bellied marmots (Marmota flaviventris), found that young breeding females in matrilines produced more daughters, and females without kin nearby produced more males. Michener (1980) found that female Richardson's ground squirrels (Urocitellus richardsonii) that produced more females maintained matrilines over generations, whereas those producing 568 fewer females did not. More recently, Yao \& Hare (2021) suggested that litter sex ratio in this 569 species varied with litter size and female experience (first-time, second or third litters produced) (but see Gedir \& Michener 2014), indicating possible complex adjustments related to resource competition and matriline maintenance. In alpine marmots (Marmota marmota),

572 females without kin helpers produce significantly more of that sex (male) in their litters 573 (Allaine et al. 2000; Allaine 2004). The presence or absence of close kin clearly has an 
influence on the sex ratio of offspring in this group of rodents (viz., marmotines), but the influences and effects appear to vary from species to species.

Given the variation among species in likely influences on sex ratios and allocation of

resources to the sexes of offspring, multiple influences in Columbian ground squirrels should

578 not be surprising. In addition, skewed sex ratios could also occur because of differential susceptibility of male and female foetuses to in utero environments and stress (Vandenbergh \& Huggett 1994; Schacht et al. 2019; Firman 2020). In our study, two factors appeared most influential, the relative body condition of mothers when breeding commenced (a strong influence on reproductive success; Dobson et al. 1999; Broussard 2005), and how many cobreeding close kin these females shared (another major influence on reproduction and fitness;

584 Viblanc et al. 2010; Dobson et al. 2012). Mothers in superior body condition in a strong matriline produced more sons. Mothers in good condition but little or no matriline advantages produced more female offspring, perhaps favoring a stronger future matriline advantage. Mothers in relatively poor condition but with strong networks of close kin produced more daughters, while those with no or few co-breeding kin produced more sons. Thus, variation in sex ratios among offspring are perhaps best explained by a combination of factors with demonstrated influences on reproduction.

\section{ACKNOWLEDGMENTS}

593 We are grateful to Alberta Parks, and Alberta Environment \& Parks (Fish and Wildlife

594 division) for their continued support in long-term monitoring programs. We are especially 595 grateful to the Biogeoscience Institute (especially E. Johnson, Director; A. Cunnings, Station 596 Manager; K. Ruckstuhl, Responsible Faculty), University of Calgary, for providing us with 597 field camp and laboratory facilities. A large number of field assistants over the years made our data collection possible. We thank Y. Handrich and M.-A. Forin-Wiart for previous discussions 
and suggestions on this study, and are especially grateful to B. Kotler and two anonymous

600 reviewers for their critical insights on the paper. T.B. was supported by a scholarship from the

601 Institut Pluridisciplinaire Hubert Curien during the data analyses and paper writing. The 602 research was funded by a U.S.A. National Science Foundation grant (DEB-0089473), to 603 F.S.D., a research grant from Natural Sciences and Engineering Research Council of Canada 604 to J.O.M., a CNRS Projet International de Cooperation Scientifique grant (PICS- 07143) to VAV, and a research grant from the Fondation Fyssen to V.A.V. F.S.D thanks the Institute of Advanced Studies of the University of Strasbourg for financial support through an USIAS fellowship, and the Région Grand Est and the Eurométropole de Strasbourg for the award of a 608 Gutenberg Excellence Chair.

609

\section{AUTHOR CONTRIBUTION}

611 TB analyzed the data, collected data in the field, and co-wrote the manuscript; VAV co612 designed the study, analyzed the data, collected data in the field, and co-wrote the manuscript;

613 CS co-designed the study, analyzed the data, collected data in the field, and commented on the 614 manuscript; JOM originated the long-term study, collected data in the field and commented on 615 the manuscript; FSD co-designed the study, collected data in the field and co-wrote the 616 manuscript.

617

\section{REFERENCES}

619 Allaine, D., F. Brondex, L. Graziani, J. Coulon, and I. Till-Bottraud. 2000. Male-biased sex ratio in litters of alpine marmots supports the helper repayment hypothesis. Behavioral Ecology 11:507-514.

622 Allaine, D. 2004. Sex ratio variation in the cooperatively breeding alpine marmot Marmota marmota. Behavioral Ecology 15:997-1002. 
624 Armitage, K. B. 1987a. Do female yellow-bellied marmots adjust the sex ratio of their offspring ? The American Naturalist 129:501-519.

626

627

628

629

630

631

632

633

634

635

636

637

638

639

640

641

642

643

644

645

646

647

648

Armitage, K. B. 1987b. Social dynamics of mammals: reproductive success, kinship and individual fitness. Trends in Ecology and Evolution 2:279-284.

Arnaud, C. M., F. S. Dobson, and J. O. Murie. 2012. Philopatry and within-colony movements in Columbian ground squirrels. Molecular Ecology 21:493-504.

Austad, S. N. 2015. The human prenatal sex ratio: A major surprise. Proceedings of the National Academy of Sciences of the United States of America 112:4839-40.

Balmer, A., B. Zinner, J. C. Gorrell, D. W. Coltman, S. Raveh, and F. S. Dobson. 2019. Alternative reproductive tactics and lifetime reproductive success in a polygynandrous mammal. Behavioral Ecology 30:474-482.

Bates, D., M. Mächler, B. Bolker, and S. Walker. 2015. Fitting linear mixed-effects models using lme4. Journal of Statistical Software 67:1-48. doi: 10.18637/jss.v067.i01.

Boag, D. A., and J. O. Murie. 1981. Population ecology of Columbian ground squirrels in southwestern Alberta. Canadian Journal of Zoology 59:2230-2240.

Broussard, D. R., F. S. Dobson, and J. O. Murie. 2005. The effects of capital on an income breeder: evidence from female Columbian ground squirrels. Canadian Journal of Zoology 83:546-552.

Brown, G. R. 2001. Sex-biased investment in nonhuman primates: can Trivers \& Willard's theory be tested? Animal Behaviour 61:683-694.

Cameron, E. Z., W. L. Linklater, K. J. Stafford, and C.J. Veltman. 1999. Birth sex ratios relate to mare condition at conception in Kaimanawa horses. Behavioral Ecology $10: 472-475$

Cameron, E. Z. 2004. Facultative adjustment of mammalian sex ratios in support of the Trivers-Willard hypothesis: evidence for a mechanism. Proceedings. Biological sciences 
650 Cameron, E. Z., and W. L. Linklater. 2007. Extreme sex ratio variation in relation to change 651 in condition around conception. Biology Letters 3:395-397.

652 Cameron, E. Z., P. R. Lemons, P. W. Bateman, and N. C. Bennett. 2008. Experimental 653 alteration of litter sex ratios in a mammal. Proceedings. Biological sciences 275:323-7. 654 Charnov, E. L. 1979. The Genetical Evolution of Patterns of Sexuality: Darwinian Fitness. 655 The American Naturalist 113:465-480.

656 Charnov, E. L. 1982. The theory of sex allocation. Princeton University Press, Princeton.

657 Clark, A. B. 1978. Sex ratio and local resource competition in a prosimian primate. Science $658 \quad 201: 163-5$.

659 Clutton-Brock, T. H., and G. R. Iason. 1986. Sex Ratio Variation in Mammals. The Quarterly $660 \quad$ Review of Biology 61:339-374.

661 Cockburn, A., M. P. Scott, and C. R. Dickman. 1985. Sex ratio and intrasexual kin 662 competition in mammals. Oecologia 66:427-429.

663 Cockburn A., S. Legge, and M. C. Double. 2002. Sex ratios in birds and mammals: can the 664 hypotheses be disentangled? In: Hardy, I. C. W., editor. Sex ratios: concepts and 665 research methods. Cambridge (UK): Cambridge University Press. p. 266-286.

666 Darwin, C. 1871. The Descent of man and selection in relation to sex. Modern Library, New $667 \quad$ York.

668 Delean, S., G. De'ath, and H. Marsh. 2009. Climate and maternal effects modify sex ratios in 669 a weakly dimorphic marsupial. Behavioral Ecology and Sociobiology 64:265-277.

670 Delignette-Muller, M. L., and C. Dutang. 2015. fitdistrplus: an R package for fitting 671 distributions. Journal of Statistical Software 64(4):1-34.

672 Dobson, F. S. 1982. Competition for mates and predominant juvenile male dispersal in 673 mammals. Animal Behaviour 30:1183-1192. 
674 Dobson, F. S., and J. D. Kjelgaard. 1985. The influence of food resources on life history in

675 Columbian ground squirrels. Canadian Journal of Zoology 63:2105-2109.

676 Dobson, F. S., and J. O. Murie. 1987. Interpretation of intraspecific life history patterns:

677 evidence from Columbian ground squirrels. American Naturalist 129:382-397.

678 Dobson, F. S. 1988. The limits of phenotypic plasticity in life histories of Columbian ground 679 squirrels. Pages 193-210 in M. S. Boyce, ed. Evolution of life histories of mammals. $680 \quad$ Yale University Press, New Haven, Conn.

681 Dobson, F. S. 1992. Body mass, structural size, and life-history patterns of the columbian 682 ground squirrel. The American naturalist 140:109-25.

683 Dobson, F. S., M. J. Badry, and C. Geddes. 1992. Seasonal activity and body mass of 684 Columbian ground squirrels. Canadian Journal of Zoology 70:1364-1368.

685 Dobson, F. S., T. S. Risch, and J. O. Murie.1999. Increasing returns in the life history of 686 Columbian ground squirrels. Journal of Animal Ecology 68:73-86.

687 Dobson, F. S., B. M. Way, and C. Baudoin. 2010. Spatial dynamics and the evolution of 688 social monogamy in mammals. Behavioral Ecology 21:747-752.

689 Dobson, F. S., V. A. Viblanc, C. M. Arnaud, and J. O. Murie. 2012. Kin selection in 690 Columbian ground squirrels: direct and indirect fitness benefits. Molecular Ecology 691 $21: 524-531$.

692 Dobson, F. S., J. E. Lane, M. Low, and J. O. Murie. 2016. Fitness implications of seasonal

Douhard, M., M. Festa-Bianchet, and F. Pelletier. 2016. Maternal condition and previous 695 reproduction interact to affect offspring sex in a wild mammal. Biology Letters

696 $12: 20160510$.

697 Douhard, M. 2017. Offspring sex ratio in mammals and the Trivers-Willard hypothesis: in 698 pursuit of unambiguous evidence. BioEssays 39:1700043. 
699 Emlen, S. T., and L. W. Oring. 1977. Ecology, sexual selection, and the evolution of mating systems. Science 197:215-223.

701 Endler, J. 1986. Natural Selection in the Wild. Princeton University Press, Princeton.

Festa-Bianchet, M., and D. A. Boag. 1982. Territoriality in adult female Columbian ground squirrels. Canadian Journal of Zoology 60:1060-1066.

Festa-Bianchet, M. 1996. Offspring sex ratio studies of mammals: Does publication depend upon the quality of the research or the direction of the results? Écoscience 3:42-44.

Firman, R. C. 2020. Exposure to high male density causes maternal stress and female-biased sex ratios in a mammal. Proceedings of the Royal Society B 287:20192909.

Fisher, R. A. 1930. The genetical theory of natural selection. Clarendon Press, Oxford.

Frank, S. A. 1990. Sex Allocation Theory for Birds and Mammals. Annual Review of Ecology and Systematics 21:13-55.

Gedir, J. V., and G. R. Michener. 2014. Litter sex ratios in Richardson's ground squirrels: long-term data support random sex allocation and homeostasis. Oecologia 174:12251239.

Greenwood, P. J. 1980. Mating systems, philopatry and dispersal in birds and mammals. Animal Behaviour 28:1140-1162.

Hamel, S., M. Festa-Bianchet, and S. D. Cote. 2016. Offspring sex in mountain goat varies with adult sex ratio but only for mothers in good condition. Behavioral Ecology and Sociobiology 70:123-132.

Hamilton, W. D. 1967. Extraordinary Sex Ratios. Science 156:477-488.

Hare, J. F., and J. O. Murie. 1992. Manipulation of Litter Size Reveals No Cost of squirrels. Behavioral Ecology and Sociobiology 15:97-102. 
Hewison, A. J. M., and J.-M. Gaillard. 1999. Successful sons or advantaged daughters? The Trivers-Willard model and sex-biased maternal investment in ungulates. Trends in Ecology \& Evolution 14:229-234.

Hutchinson, G. E. 1965. The Ecological Theater and the Evolutionary Play. Yale University Press, New Haven.

Johnson, C. N. 1988. Dispersal and the sex ratio at birth in primates, 332: 726-728.

King, W. J. 1989a. Kin-differential behaviour of adult female Columbian ground squirrels. Animal Behaviour 38:354-356.

King, W. J. 1989b. Spacing of female kin in Columbian ground squirrels ( Spermophilus columbianus ). Canadian Journal of Zoology 67:91-95.

King, W. J., and J. O. Murie. 1985. Temporal overlap of female kin in Columbian ground squirrels (Spermophilus columbianus). Behavioral Ecology and Sociobiology 16:337341.

Kojola, I. 1998. Sex Ratio and Maternal Investment in Ungulates. Oikos 83:567.

Kruuk, L. E., T. H. Clutton-Brock, S. D. Albon, J. M. Pemberton, and F. E. Guinness. 1999. Population density affects sex ratio variation in red deer. Nature 399:459-461.

Kruuk, L. E. B., and W. G. Hill. 2008. Introduction. Evolutioonary dynamics of wild populations: the use of long-term pedigree data. Proceedings of the Royal Scoiety B $275: 593-596$

Lande, R., and S. Arnold. 1983. The measurement of selection on correlated characters. Evolution 37:1210-1226.

Lane, J. E., L. E. B. Kruuk, A. Charmantier, J. O. Murie, and F. S. Dobson. 2012. Delayed phenology and reduced fitness associated with climate change in a wild hibernator. Nature 489:554-557.

Manno, T. G., and F. S. Dobson. 2008. Why are Male Columbian Ground Squirrels 
Michener, G. R. 1980. Differential reproduction among female Richardson's ground squirrels and its relation to sex ratio. Behavioral Ecology and Sociobiology 7:173-178.

Murie, J. O., and M. A. Harris. 1982. Annual Variation of Spring Emergence and Breeding in Columbian Ground Squirrels (Spermophilus columbianus). Journal of Mammalogy 63:431-439.

Murie, J. O., and M. A. Harris. 1988. Social interactions and dominance relationships

Murie, J. O. 1995. Mating behavior of Columbian ground squirrels. I. Multiple mating by between female and male Columbian ground squirrels. Canadian Journal of Zoology

Neuhaus, P. 2006. Causes and consequences of sex-biased dispersal in Columbian ground squirrel, Spermophilus columbianus. Behaviour 143:1013-1031.

R Core Team. 2020. R: A language for statistical computing. R Foundation for Statistical Computing, Vienna, Austria.

Raveh, S., D. Heg, F. S. Dobson, D. W. Coltman, J. C. Gorrell, A. Balmer, and P. Neuhaus. 2010. Mating order and reproductive success in male Columbian ground squirrels (Urocitellus columbianus). Behavioral Ecology 21:537-547.

Raveh, S., D. Heg, V. A. Viblanc, D. W. Coltman, J. C. Gorrell, F. S. Dobson, A. Balmer, and P. Neuhaus. 2011. Male reproductive tactics to increase paternity in the polygynandrous Columbian ground squirrel (Urocitellus columbianus). Behavioral test in Columbian ground squirrels. Ecology 76:1643-1654. 
Robert, K. A., and L. E. Schwanz. 2011. Emerging sex allocation research in mammals: marsupials and the pouch advantage. Mammal Review 41:1-22 .

Roff, D. A. 2001. Life History Evolution. Oxford University Press, Oxford.

Rubach, K., M. Wu, A. Abebe, F. S. Dobson, J. O. Murie, and V. A. Viblanc. 2016. Testing the reproductive and somatic trade-off in female Columbian ground squirrels. Ecology and Evolution 6:7586-7595.

Schacht, R., D. Tharp, and K. R. Smith. 2019. Sex ratios at birth vary with environmental harshness but not maternal condition. Scientific reports 9: 1-7.

Schindler, S., J. Gaillard, A. Grüning, P. Neuhaus, L. W. Traill, S. Tuljapurkar, and T. Coulson. 2015. Sex-specific demography and generalization of the Trivers-Willard theory. Nature 526:249-252.

Schwanz, L. E., and K. A. Robert. 2014. Proximate and ultimate explanations of mammalian sex allocation in a marsupial model. Behavioral Ecology and Sociobiology 68:10851096.

Sheldon, B. C., and S. A. West. 2004. Maternal dominance, maternal condition, and offspring sex ratio in ungulate mammals. American Naturalist 163:40-54.

Silk, J. B. 1983. Local Resource Competition and Facultative Adjustment of Sex Ratios in Relation to Competitive Abilities. The American Naturalist 121:56-66.

Simpson, M. J. A., and A. E. Simpson. 1982. Birth sex ratios and social rank in rhesus monkey mothers. Nature 300:440-441.

Skibiel, A. L., F. S. Dobson, and J. O. Murie. 2009. Maternal influences on reproduction in two populations of Columbian ground squirrels. Ecological Monographs 79:325-341.

Stearns, S. C. 1992. The Evolution of Life Histories. Oxford University Press, Oxford. 
Steven, S. D. 1998. High incidence of infanticide by lactating females in a population of

797 Columbian ground squirrels (Spermophilus columbianus). Canadian Journal of Zoology

798

799

800

801

802

803

804

805

806

807

808

809

810

811

812

813

814

815

816

817

818

819

820 76:1183-1187.

Stoffel, M. A., S. Nakagawa, and H. Schielzeth. 2017. rptR: repeatability estimation and variance decomposition by generalized linear mixed-effects models. Methods in Ecology and Evolution 8:1639-1644.

Toni, P., D. Forsyth, and M. Festa-Bianchet. 2021. Determinants of offspring sex in kangaroos: a test of multiple hypothesesBehavioral Ecology, in press.

Trivers, R., and D. Willard. 1973. Natural selection of parental ability to vary the sex ratio of offspring. Science 179:90-92.

Vandenbergh, J. G., and C. L. Huggett. 1994. Mother's prior intrauterine position affects the sex ratio of her offspring in house mice. Proceedings of the National Academy of Sciences USA, 91: 11055-11059.

Viblanc, V. A., C. M. Arnaud, F. S. Dobson, and J. O. Murie. 2010. Kin selection in Columbian ground squirrels ( Urocitellus columbianus ): littermate kin provide individual fitness benefits. Proceedings of the Royal Society B: Biological Sciences 277:989-994.

Viblanc, V. A., C. Pasquaretta, C. Sueur, R. Boonstra, and F. S. Dobson. 2016. Aggression in Columbian ground squirrels: relationships with age, kinship, energy allocation, and fitness. Behavioral Ecology 27:1716-1725.

Wells, C. P., and D. H. Van Vuren. 2017. Female kin density affects offspring sex ratio in an asocial mammal, the golden-mantled ground squirrel, Callospermophilus lateralis. Animal Behaviour 134:71-77.

West, S. A. 2009. Sex allocation. Princeton University Press, Princeton.

Wiggett, D. R., and D. A. Boag. 1992. Natal dispersal in Columbian ground squirrels: is body 

mass the proximate stimulus? Canadian Journal of Zoology 70:649-653.

822 Yeo, A. R., and J. F. Hare. 2021. Richardson's ground squirrel litter size-sex ratio trade-off 823 reveals conditional adaptive sex allocation 195: 915-925.

824 Zuur, A. F., E. N. Ieno, and C. S. Elphick. 2010. A protocol for data exploration to avoid 825 common statistical problems. Methods in Ecology and Evolution 1:3-14.

826

827

828 
831 Fig 1. Annual offspring sex ratio (\% males) at weaning in the Columbian ground squirrel

832 (Urocitellus columbianus) from 1992 to 2020. The black line represents the mean litter sex ratio for mothers (mean of individual mother values $=51.3 \%$ ) in the population each year with associated $95 \% \mathrm{CI}$ obtained by bootstrap (1000 simulations, 50\% of the litters resampled each time). The blue dotted line represents the sex ratio of all offspring at weaning in the entire

836 population (total number of weaned males / (total number of weaned males + total number of weaned females)). A sex ratio above 50\% (solid black horizontal line) is biased towards males, and below, towards females.

Fig 2. Offspring mass (in grams) at (A) birth and (B) weaning according to sex in the

841 Columbian ground squirrel. Boxplots present the median, 25 and 75 percentiles of the

842 distribution. Red dots and lines present the marginal estimated means and 95\% CI for female and male offspring mass, accounting for litter size at birth and weaning, respectively (see Models in text).

846 Fig 3. Offspring mass gain (g) over the lactation period as a function of (A) offspring sex, (B)

847 offspring mass at birth (standardized), (C) maternal mass at the start of the breeding season 848 (standardized), (D) litter size at birth (standardized), and (E) lactation duration (in days, 849 standardized) in Columbian ground squirrels. Boxplots present the median, 25 and 75 850 percentiles of the distribution. Red dots and lines present the marginal estimated means and $85195 \%$ CI for female and male offspring mass, accounting for all other effects in the model. 852 Linear relationships show the raw data points and the predicted effect with $95 \%$ confidence intervals, also accounting for the other effects in the model (see text). 
855 Fig 4. Interaction plot representing the effects of maternal relative condition within years

856 (standardized, see Methods) on litter sex ratio at weaning as a function of number of kin 857 present. The line and 95\% confidence intervals were computed from a Generalized Linear 858 Model that examined litter sex ratio at weaning as a matrix of count data, i.e. matrix of 859 "success" and "failures" with male = "success", female = "failure." 


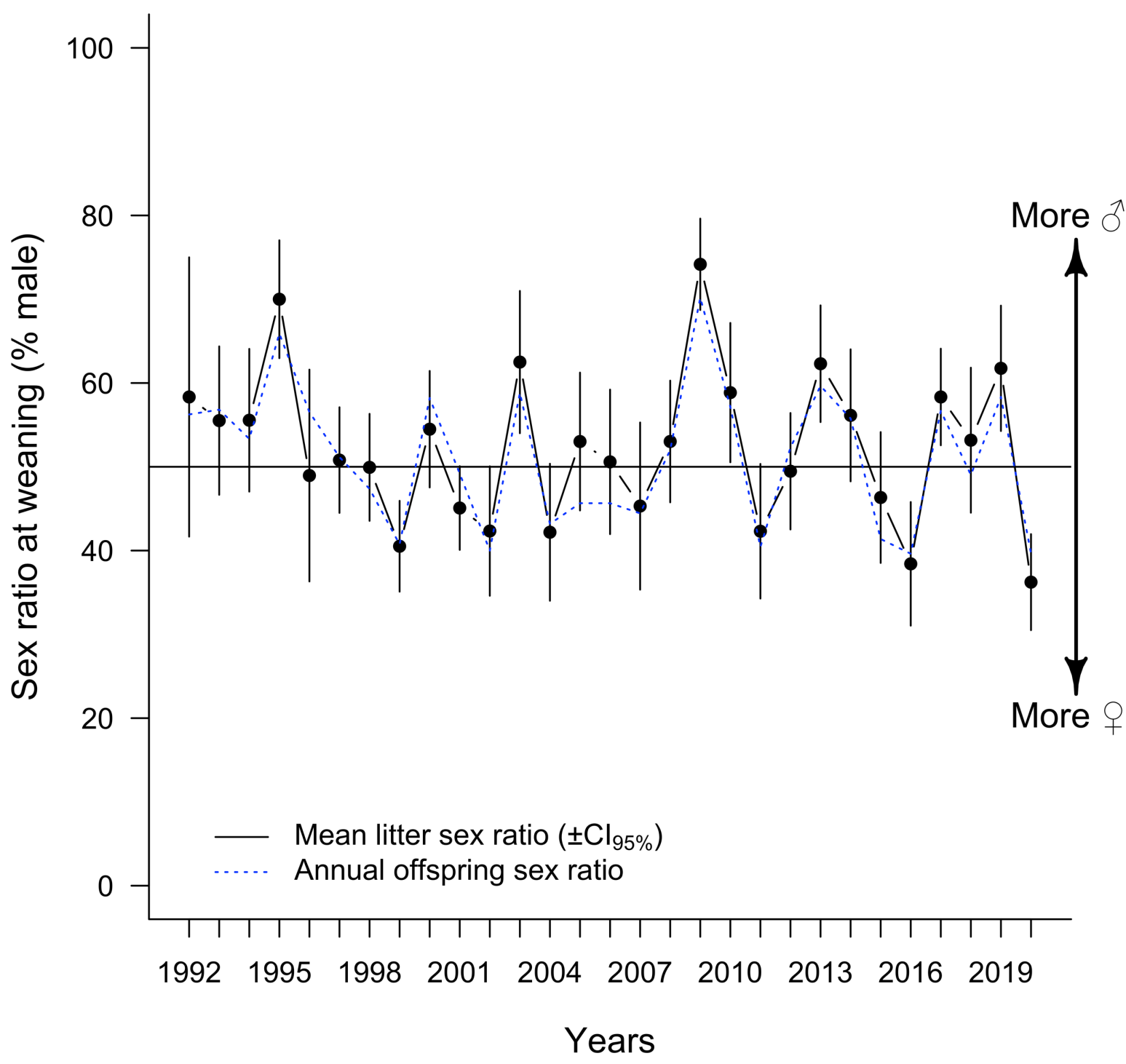

861

862

$863 \quad$ Fig 1.

864

865

866

867

868 

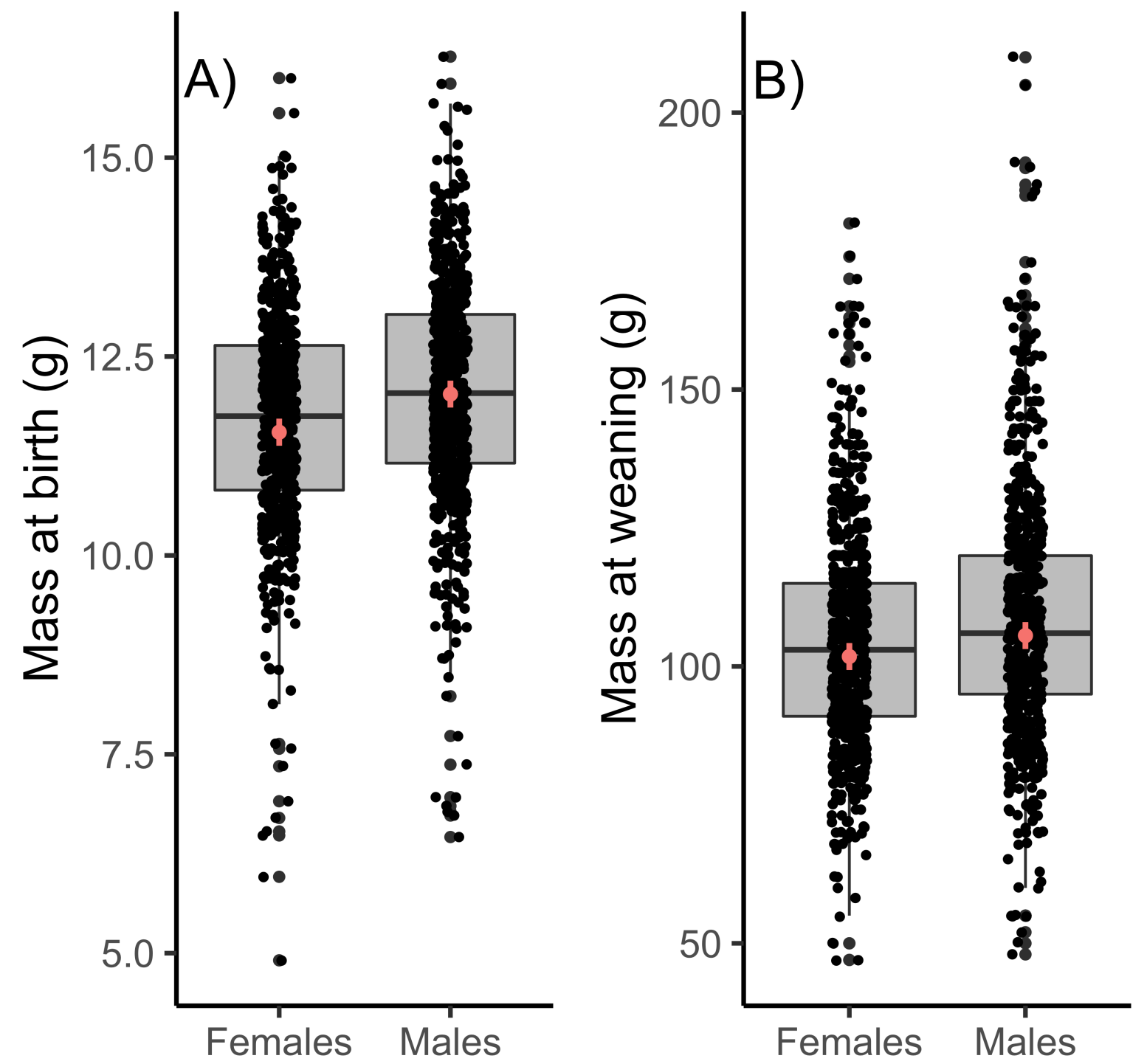

869

$870 \quad$ Fig 2.

871

872 

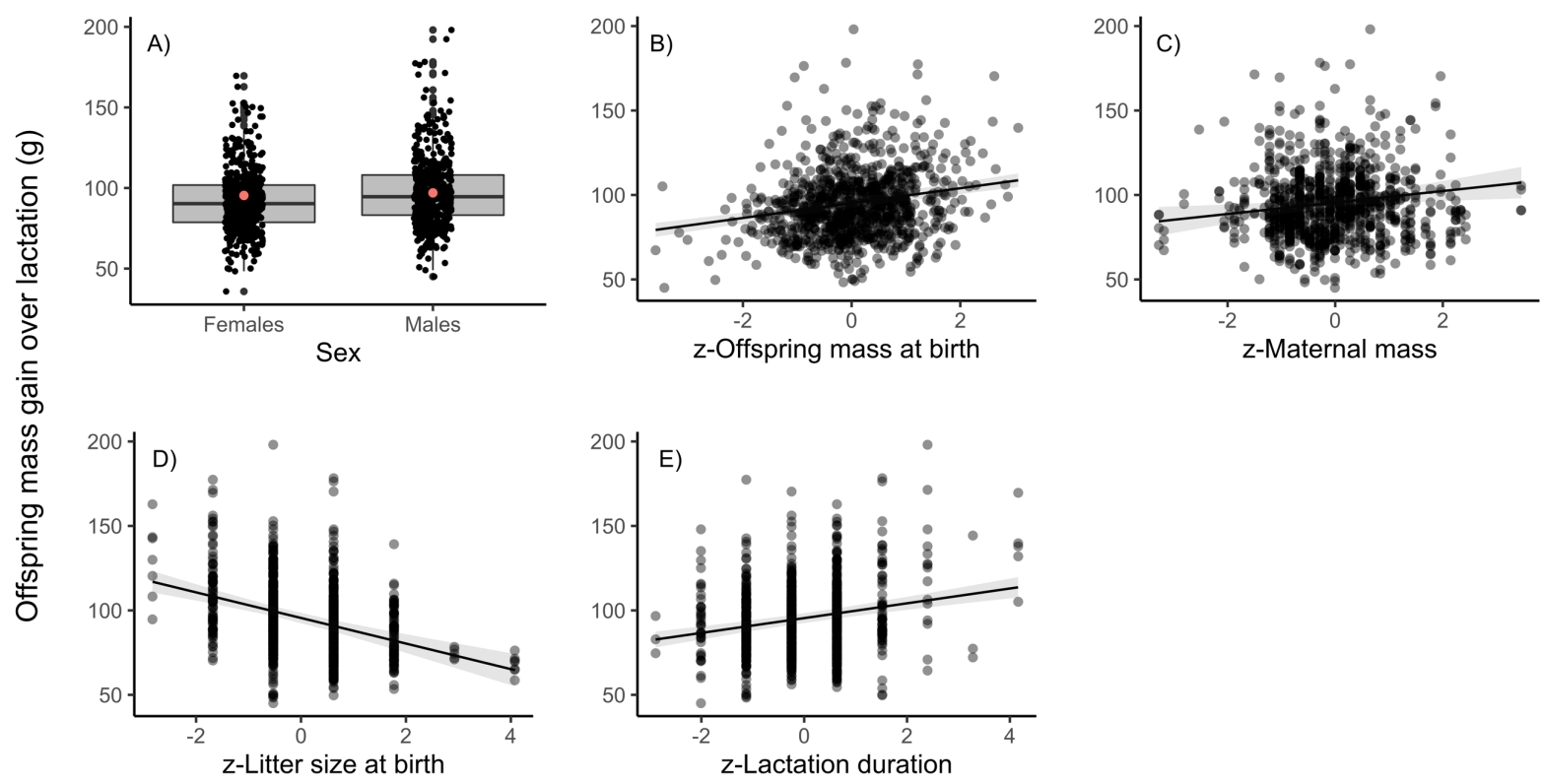

874

$875 \quad$ Fig 3.

876

877

878

879

880

881

882

883

884

885

886

887

888

889

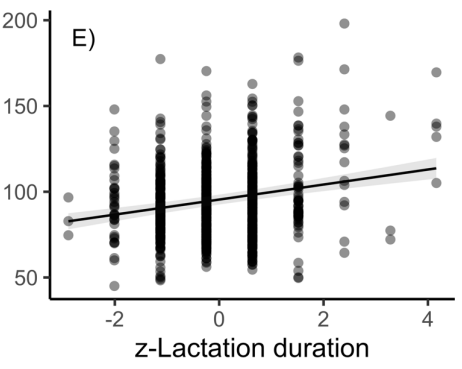




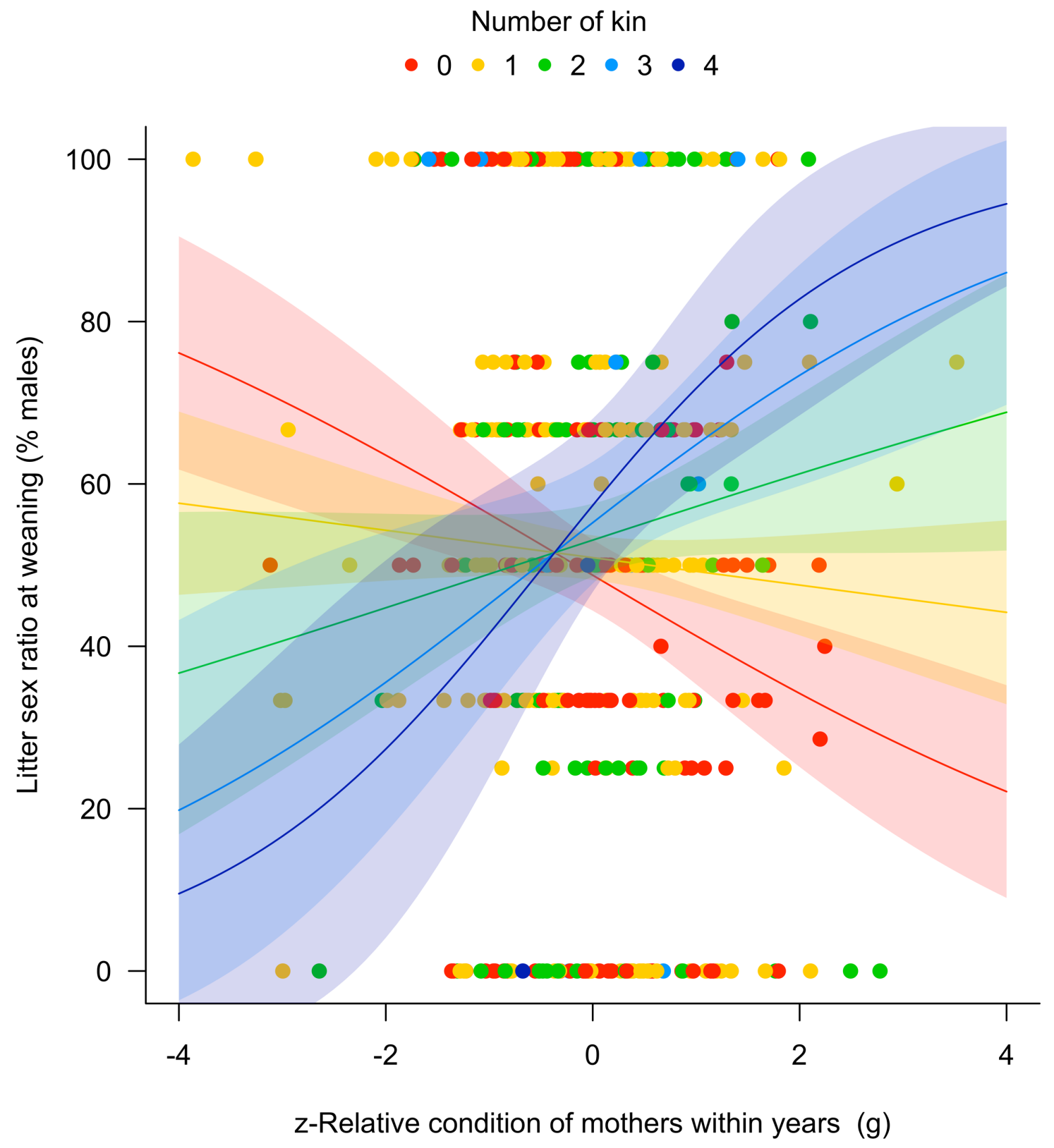

890

891

$892 \quad$ Fig 4.

893 